\title{
Influence of HTLV-1 on the clinical, microbiologic and immunologic presentation of tuberculosis
}

\author{
Maria de Lourdes Bastos ${ }^{1,2,3}$, Silvane B Santos ${ }^{1}$, Anselmo Souza', Brooke Finkmoore ${ }^{4}$, Ohana Bispo ${ }^{1,2}$, \\ Tasso Barreto ${ }^{1,2}$, Ingrid Cardoso 1,2, lana Bispo ${ }^{1,2}$, Flávia Bastos ${ }^{1,2}$, Daniele Pereira ${ }^{1,2}$, Lee Riley ${ }^{4}$ \\ and Edgar M Carvalho $1,2,5,6^{*}$
}

\begin{abstract}
Background: HTLV-1 is associated with increased susceptibility to Mycobacterium tuberculosis infection and severity of tuberculosis. Although previous studies have shown that HTLV-1 infected individuals have a low frequency of positive tuberculin skin test (TST) and decreasing in lymphoproliferative responses compared to HTLV-1 uninfected persons, these studies were not performed in individuals with history of tuberculosis or evidence of $M$. tuberculosis infection. Therefore the reasons why HTLV-1 infection increases susceptibility to infection and severity of tuberculosis are not understood.The aim of this study was to evaluate how HTLV-1 may influence the clinical, bacteriologic and immunologic presentation of tuberculosis.

Methods: The study prospectively enrolled and followed 13 new cases of tuberculosis associated with HTLV-1 (cases) and 25 patients with tuberculosis without HTLV-1 infection (controls). Clinical findings, bacterial load in the sputum, $x$-rays, immunological response and death were compared in the two groups.

Results: There were no differences in the demographic, clinical and TST response between the two study groups. IFN- $\gamma$ and TNF-a production was higher in unstimulated cultures of mononuclear cells of case than in control patients $(p<0.01)$. While there was no difference in IFN- $\gamma$ production in PPD stimulated cultures, TNF-a levels were lower in cases than in controls $(p=0.01)$. There was no difference in the bacterial load among the groups but sputum smear microscopy results became negative faster in cases than in controls. Death only occurred in two co-infected patients.

Conclusion: While the increased susceptibility for tuberculosis infection in HTLV-1 infected subjects may be related to impairment in TNF-a production, the severity of tuberculosis in co-infected patients may be due to the enhancement of the Th1 inflammatory response, rather than in their decreased ability to control bacterial growth.
\end{abstract}

Keywords: HTLV-1, Tuberculosis, Mycobacterium tuberculosis

\section{Background}

The human T cell lymphotropic virus type 1 (HTLV-1) has a worldwide distribution; it is most prevalent in Central and South America, Central Africa and southwestern Japan [1]. HTLV-1 infects predominantly CD4 T cells inducing cell activation and proliferation of both CD4 and CD8 T cells [2,3]. Moreover, the high production of pro-inflammatory cytokines (TNF- $\alpha$ and IFN- $\gamma$ )

\footnotetext{
*Correspondence: edgar@ufba.br

${ }^{1}$ Serviço de Imunologia do Complexo Hospitalar Universitário Professor Edgard Santos, Universidade Federal da Bahia, Salvador, BA, Brazil ¿Escola Bahiana de Medicina e Saúde Pública, Salvador, BA, Brazil Full list of author information is available at the end of the article
}

has been associated with central nervous system (CNS) damage and the development of HTLV-1 associated myelopathy (HAM) [2,3].

There is evidence that HTLV-1 infection increases severity and susceptibility to strongyloidiasis, scabies and tuberculosis [4-9]. In patients co-infected with HTLV-1 and Strongyloides stercoralis the exaggerated Th1 immune response and increased regulatory $\mathrm{T}$ cell response decrease the Th2 immune response, which plays a pivotal role in host defense against helminthes [9-12]. HTLV-1 infected individuals have two to four-fold increased chance to acquire tuberculosis [6,13-15]. Additionally, in one retrospective study, it was observed that

\section{Biomed Central}


HTLV-1 increased the mortality rate of tuberculosis [8]. Since the frequency of responders to tuberculin skin test (TST) [16-18] and in vitro lymphocyte proliferation stimulated by protein purified derivate (PPD) is lower among HTLV-1 infected individuals with tuberculosis than in HTLV-1 uninfected persons [19], it has been proposed that a decrease in type 1 immune response to mycobacterial antigen may increase tuberculosis susceptibility and severity. In this study the clinical, radiologic, immunologic, and bacteriologic features of patients with tuberculosis and HTLV-1 infection were compared with those who had only tuberculosis infection.

\section{Results}

There was no significant difference in the demographic characteristics (age, gender, ethnicity, monthly income and nutritional status) between the 13 patients with tuberculosis and HTLV-1 infection and 25 patients with only tuberculosis. A large proportion of case (54\%) and control patients $(64 \%)$ were underweight (body mass index $<18.4$ ) and the use of alcohol was also similar in both groups. The clinical manifestations, response to TST and the presence and quantification of acid-fast bacilli (AFB) in the sputum in the two groups are shown on Table 1. The presence of fever, asthenia, anorexia and weight loss were similar in the two groups $(\mathrm{p}>0.05)$. In both groups the frequency of hospitalization for tuberculosis, previous tuberculosis and treatment abandonment for tuberculosis was high. There was no difference regarding the frequency of responders to the TST as well as the size of induration. At the time of admission, two patients with HTLV-1 infection and tuberculosis had been receiving therapy for tuberculosis for 28 and 35 days, respectively; in both, the sputum test was negative. However, previous to the therapy, both were documented to have AFB in the sputum, which also grew M. tuberculosis in culture. They were admitted because of toxicity to antituberculosis drugs. No difference in the bacillary load was observed in the two groups at admission. The drug sensibility test revealed one $M$. tuberculosis isolate with multidrug resistance and another with resistance to isoniazid and streptomycin among the cases. In the control group, there was one isolate with resistance to isoniazid, rifampicin and ethambutol and one with resistance to streptomycin. The findings of the chest $\mathrm{x}$-rays were similar in the 2 groups. Cavitation was observed in more than $60 \%$ of the patients with or without HTLV-1 infection. Fibrosis and atelectasis occurred in about $50 \%$ of the cases and controls. Parenchymal destruction was higher (15.3\%) in patients with HTLV-1 infection and tuberculosis than in patients with only tuberculosis. The radiologic findings in patients with HTLV-1 and tuberculosis were not compatible with those observed in patients with $\mathrm{T}$ cell impairment. The most common

Table 1 Clinical and microbiologic characteristics of tuberculosis patients with or without HTLV-1 infection

\begin{tabular}{|c|c|c|c|}
\hline Characteristic & $\frac{\frac{\text { TB with HTLV-1 }}{(n=13)}}{n(\%)}$ & $\frac{\frac{\text { TB without HTLV-1 }}{(n=25)}}{\mathrm{n}(\%)}$ & p-value \\
\hline \multicolumn{4}{|l|}{ Symptoms } \\
\hline Fever & $11(84.6)$ & $21(84.0)$ & 0.67 \\
\hline Asthenia & $13(100)$ & $25(100)$ & - \\
\hline Anorexia & $11(84.6)$ & $21(84.0)$ & 0.35 \\
\hline Weight loss & $11(100)$ & $22(95.7)$ & - \\
\hline Prior hospitalization for TB & $6(46.2)$ & $7(28.0)$ & 0.26 \\
\hline Prior treatment for TB & $7(53.8)$ & $12(48.0)$ & 0.21 \\
\hline History of treatment abandonment & $6(46.2)$ & $7(28.0)$ & 0.45 \\
\hline \multicolumn{4}{|l|}{ Clinical examinations } \\
\hline Helminth infections & $2(15.4)$ & $3(12)$ & 0.63 \\
\hline PPD positive & $10(76.9)$ & $14(63.6)$ & 0.71 \\
\hline Mean PPD $(\mathrm{mm})$ among PPD positive tests, \pm SD & $12.9 \pm 4.0$ & $10.5 \pm 4.8$ & 0.23 \\
\hline \multicolumn{4}{|l|}{ Sputum bacillary load } \\
\hline 0 & $2(15.4)^{*}$ & $0(0)$ & \\
\hline $1+$ & $5(38.4)$ & $11(44.0)$ & \\
\hline $2+$ & $2(15.4)$ & $3(12.0)$ & \\
\hline $3+$ & $4(30.8)$ & $11(44.0)$ & \\
\hline
\end{tabular}

$\mathrm{TB}=$ tuberculosis; HTLV-1 = human lymphotropic virus type 1; $\mathrm{SD}=$ standard deviation.

The two patients had already been treated for tuberculosis for one month previous to the admission. Before therapy the smear microscopy result was positive. 
findings were fibrosis, atelectasis, pleural thickening and cavitation. All of them were similar in the two groups but the parenchymal destruction lesions were 3.5 fold higher in patients with HTLV-1 infection and tuberculosis than in patients only with tuberculosis.

The therapy for tuberculosis was similar in both groups. The majority of the patients received rifampicin, isoniazid and pyrazinamide. In $33.3 \%$ of the cases and in $28 \%$ of the controls, patients also received ethambutol. Alternative drugs were given to $15.4 \%$ of the cases and to $8 \%$ of controls.

Figure 1 shows the survival analysis of patients whose sputum test became negative after 10 and 20 days of therapy. As previously stated, two patients with HTLV-1 infection and tuberculosis were already on therapy and the sputum test was negative. On day 10 , while $50 \%$ of the patients with tuberculosis and HTLV-1 still had AFB in the sputum, almost $90 \%$ of patients with tuberculosis only remained eliminating bacilli. At day 20, $36.4 \%$ of the patients with HTLV-1 infection and tuberculosis and $75 \%$ of those with tuberculosis only were smear test positive for AFB ( $\mathrm{p}=0.07$; Kaplan-Meier test). However, sputum test conversion occurred faster in patients with HTLV-1 infection and tuberculosis.

The main side effects observed were hepatotoxicity and gastric intolerance (nausea, abdominal pain and vomit) observed in, respectively, $38.5 \%$ and $23.1 \%$ in the cases and in $28 \%$ and $36 \%$ in the controls ( $p>0.05)$. While death was observed in $2(15.4 \%)$ of the patients with HTLV-1 infection and tuberculosis, none of the patients died in the group only with tuberculosis. Death occurred in one woman and one man. They both had cavitary lung disease, fibrosis, atelectasis and tissue

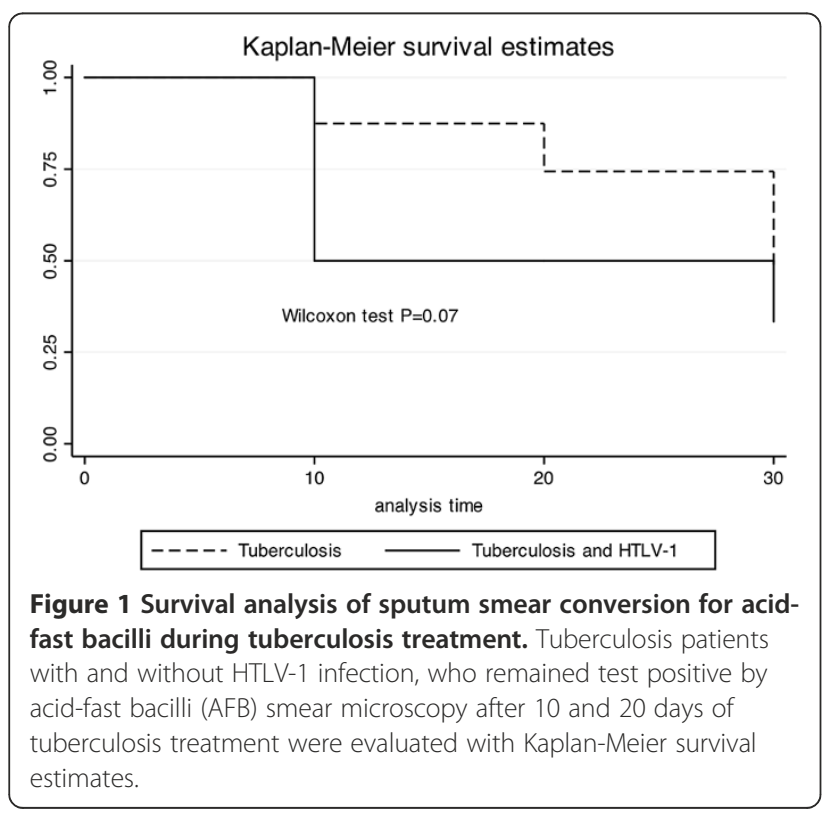

destruction on chest $\mathrm{x}$-rays. Death was due to acute respiratory insufficiency in one case and sepsis in the other.

Regarding HTLV-1 infection, the majority of the cases were HTLV-1 carriers. Four patients had overactive bladder that is considered to be an oligosymptomatic form of HAM. The proviral load was quite variable ranging from 8079 to 499742 copies $/ 10^{6}$ cells.

The spontaneous and PPD induced TNF- $\alpha$ and INF- $\gamma$ production in supernatants of PBMC are shown in Figure 2. In cultures without stimulus, the median TNF- $\alpha$ level among the group with HTLV-1 infection and tuberculosis (368 pg/mL) ranging from 128 to $5527 \mathrm{pg} / \mathrm{mL}$ was higher $(\mathrm{p}=0.004)$ than that observed in patients with only tuberculosis $(73 \mathrm{pg} / \mathrm{mL})$, which ranged from 0 to $738 \mathrm{pg} / \mathrm{mL}$ (Figure 2A). In cultures stimulated with PPD, the median and range of TNF- $\alpha$ level in the coinfected patients, $0 \mathrm{pg} / \mathrm{mL}(0-2295 \mathrm{pg} / \mathrm{mL})$, was lower $(\mathrm{p}<0.01)$ than in patients with only tuberculosis, which was $386 \mathrm{pg} / \mathrm{mL}(0-3847 \mathrm{pg} / \mathrm{mL})$ (Figure $2 \mathrm{~B})$. The production of IFN- $\gamma$ in unstimulated cultures in patients with HTLV-1 infection and tuberculosis $732 \mathrm{pg} / \mathrm{mL}(0-$ $2677 \mathrm{pg} / \mathrm{mL})$ was higher $(\mathrm{p}=0.004)$ than in patients with only tuberculosis, which was $15 \mathrm{pg} / \mathrm{mL}(0-444 \mathrm{pg} / \mathrm{mL})$ (Figure $2 \mathrm{C}$ ). There was no difference between the groups in the production of IFN- $\gamma$ in PPD stimulated cultures (Figure 2D). There was no difference $(p>0.05)$ in the production of IL-10 in both unstimulated and PPD stimulated cultures; majority of the co-infected patients $(60 \%)$ and $45 \%$ of patients with tuberculosis without HTLV-1 infection had no detectable IL-10 production (data not shown). Addition of anti-IL-10 monoclonal antibody also did not enhance IFN- $\gamma$ production $(p>0.05)$ in either group (data not shown).

The expression of mRNA for IL-12 in unstimulated cultures and the production of IFN- $\gamma$ in PBMC cultures stimulated with PPD and in cultures with PPD plus exogenous addition of IL-12 are shown in Figure 3. The expression of mRNA for IL-12 in unstimulated cultures was lower in tuberculosis patients with or without coinfection with HTLV-1 than in seronegative controls (Figure 3A). Exogenous addition of IL-12 in cultures stimulated with PPD enhanced IFN- $\gamma$ production similarly in both groups (Figures 3, B and C).

\section{Discussion}

The association between HTLV-1 infection and tuberculosis is widely documented, but little is known about the influence of HTLV-1 on the outcome of M. tuberculosis infection [6,13-15]. In the present study, the two cases of death occurred among co-infected patients, but no impairment in the $\mathrm{T}$ cell response to PPD was observed in vivo and in vitro. However, while there was decrease in TNF- $\alpha$ production in PPD stimulated cultures, the 


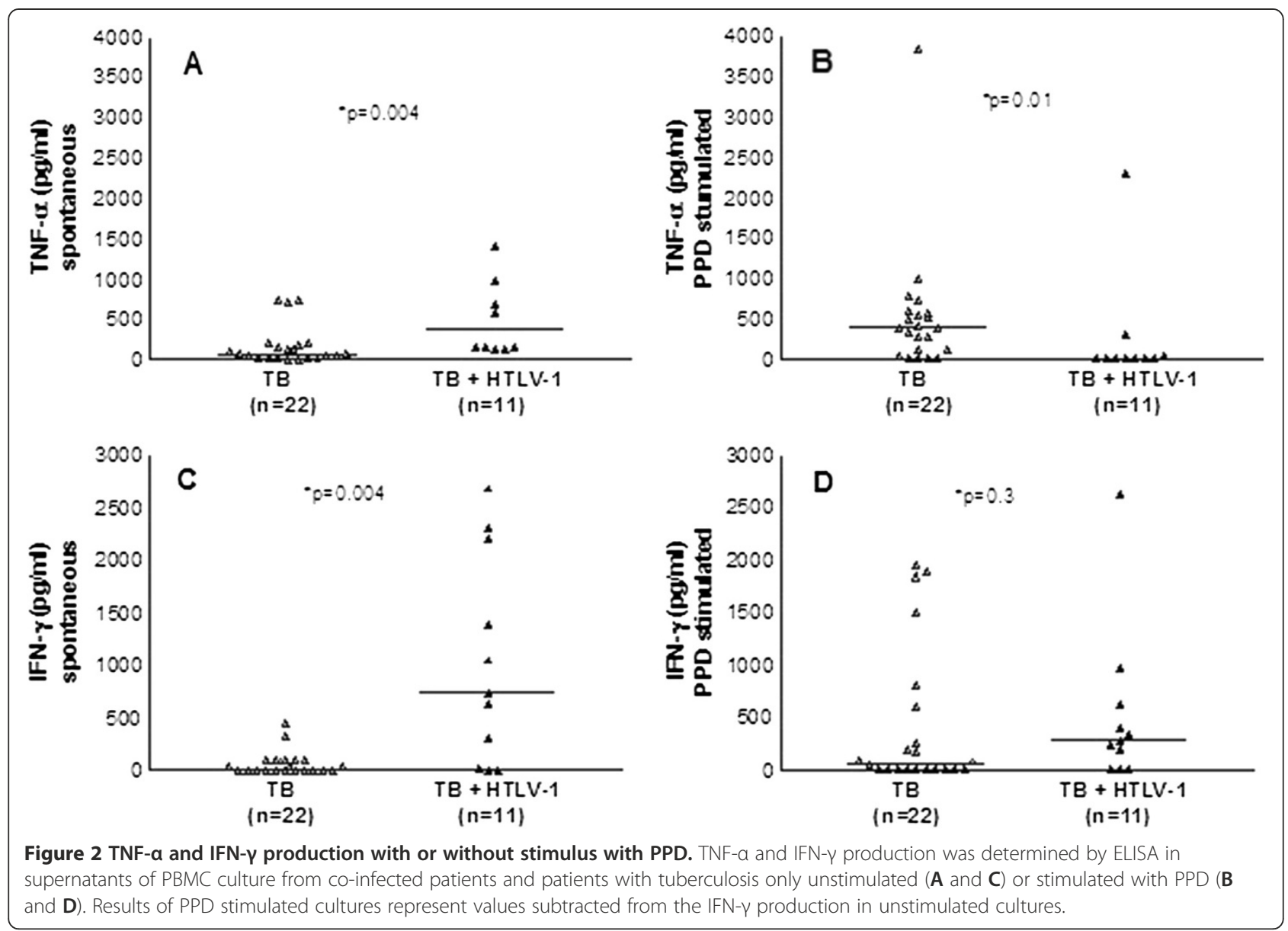

INF- $\gamma$ production in unstimulated cultures was higher in co-infected patients than in patient only with tuberculosis. These data together with the observation that the sputum smear conversion was faster in the cases compared to controls, suggests that impairment in innate immune response may contribute to acquisition of tuberculosis, and that severity of the disease may be due to exaggerated inflammatory response observed in coinfected patients.

One important limitation of the present study was the characteristics of patients with tuberculosis. The admission for tuberculosis patients is usually due to severity of disease, severe adverse reactions to anti-tuberculosis drugs, history of treatment abandonment and documentation of multidrug-resistant M. tuberculosis [20]. In our case, in addition to the presence of one or more of these factors, a large percentage of the patients were underweight and malnourished, which may have also influenced the clinical course of tuberculosis. Therefore, a similar type of the study should be performed in outpatients with less severe tuberculosis manifestations to determine if the viral infection may change the symptoms and $\mathrm{x}$-rays findings of tuberculosis. Nevertheless, since the frequency of these factors was similar in tuberculosis patients co-infected or not with HTLV-1, this study gives support to the previous observation that HTLV-1 infection worsens the course of tuberculosis [8].

While there is good evidence that HTLV-1 infection increases the risk for tuberculosis [6,13-15], very little is known about the clinical course of tuberculosis in such patients. In a retrospective study, it was shown that death was significantly more frequent in patients with tuberculosis and HTLV-1 infection than in patients who had only tuberculosis $[8,14]$. However no information regarding microbiological, radiological or clinical data were provided to determine how HTLV-1 can exacerbate the clinical course of tuberculosis. As previous studies have shown that subjects infected with HTLV-1 have a decreased immune response "in vivo" and "in vitro" to PPD [17-19,21], one possibility is that HTLV-1, by decreasing the immune response to $M$. tuberculosis, not only increases susceptibility but also makes tuberculosis more severe. The results presented here did not show any difference in the frequency of patients who respond to the TST as well as in the size of the induration when the two groups were compared. These data differ from the literature, but the population studied here was quite different from those included in previous studies. In the 


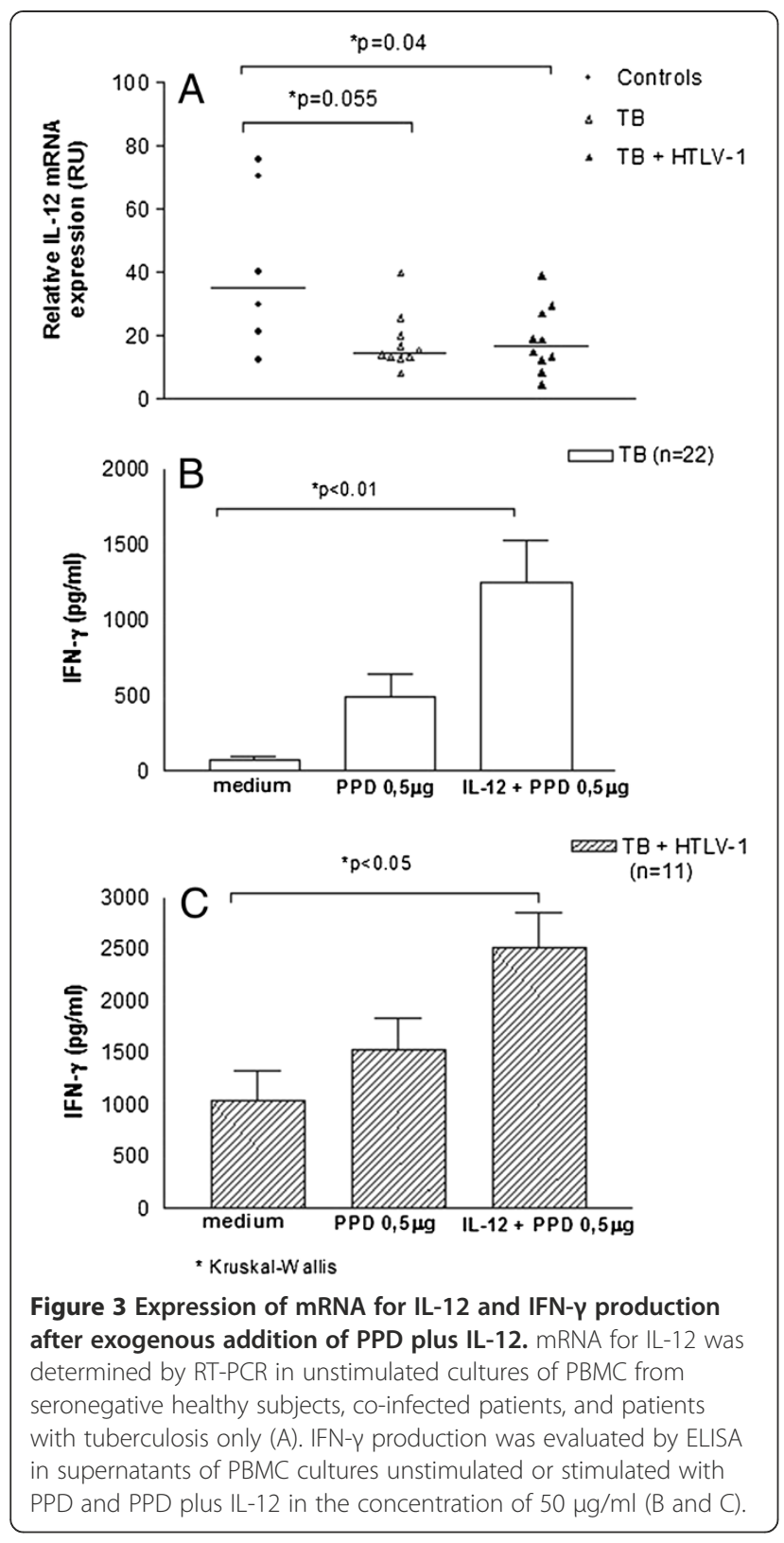

other studies, data were generated from HTLV-1 infected subjects without documented active tuberculosis or even without history of tuberculosis or vaccination with BCG [16-18]. Here all patients had active tuberculosis as documented microbiologically.

In vitro studies showed decrease in lymphocyte proliferation and secretion of cytokines upon stimulation with M. tuberculosis antigen in HTLV-1 infected subjects compared to controls $[19,21]$. Similar to the in vivo observations, the in vitro studies were also performed in HTLV-1 infected patients without history of tuberculosis. However, it is known that abnormalities in $\mathrm{T}$ cell or in antigen present cell function occur in HTLV-1 infection [21-23]. Therefore impairment in the Th1 type of immune response to mycobacterial antigens may increase susceptibility to tuberculosis. However, our clinical radiologic, microbiologic and immunologic data did not show any evidence of impairment in the $\mathrm{T}$ cell immune response to mycobacterial antigens in patients with tuberculosis and HTLV-1 infection. For instance patients with HIV infection have impairment in granuloma formation, atypical chest $\mathrm{x}$-ray findings, and slower time to bacterial conversion [24]. Here all patients had AFB in the sputum. The majority had cavitation and fibrosis on chest $\mathrm{x}$-ray, and parenchymal destruction was more frequent in patients with tuberculosis and HTLV-1 infection. These are findings observed in immunocompetent patients with tuberculosis. Moreover, there was no difference in the frequency and size of the TST and there was no difference in IFN- $\gamma$ production in the two groups in PPD stimulated cultures. Others have found increase in bacillary load in patients with HTLV-1 infection and tuberculosis [14]. In this study we did not find any difference in the bacillary load, and the sputum test became negative faster in patients with tuberculosis coinfected with HTLV-1. Thus, the exaggerated inflammation with HTLV-1 infection may have contributed to the rapid sputum smear conversion and to the severity of tuberculosis. For instance mice lacking IL-27 receptors and mice infected with a $M$. tuberculosis mce1 operon mutant cannot modulate immune response and mount an exaggerated inflammatory response associated with control of bacterial multiplication, but survival is decreased due to severe damage of the lung $[25,26]$.

Compared to seronegative controls, expression of IL12 was lower in both groups and exogenous addition of IL-12 enhanced IFN- $\gamma$ production in a similar way in tuberculosis patients co-infected with HTLV-1 and in patients with tuberculosis. However, while there was no difference in IFN- $\gamma$ production among the groups, in PPD stimulated cultures, TNF- $\alpha$ was lower in PPD stimulated cultures of patients co-infected with M. tuberculosis and HTLV-1. TNF- $\alpha$ plays a key role in protection against M. tuberculosis [27,28]. Actually emphasis has been given for the important role of innate immune response in the control of $M$. tuberculosis infection $[29,30]$. In such a case, the increased susceptibility of HTLV-1 infected individuals to $M$. tuberculosis may be due to impairment in TNF- $\alpha$ synthesis after exposure to $M$. tuberculosis, as well as in other component of the immune response not yet determined. However, as IFN$\gamma$ production is produced in high levels in HTLV-1 infection and a type 1 immune response to $M$. tuberculosis antigens is not suppressed, granuloma formation is observed and bacterial growth is controlled. Additionally, as HTLV-1 infection is associated with an exaggerated inflammatory response, there is more tissue 
damage, which causes severer tuberculosis in HTLV-1 infected subjects.

\section{Conclusions}

While the increased susceptibility of HTLV-1 infected patients to acquire tuberculosis may be due to impaired TNF- $\alpha$ production, the severity of tuberculosis in HTLV-1 infected individuals may be related to an increased inflammatory response.

\section{Methods}

The study participants included 13 patients with diagnosis of tuberculosis and HTLV-1 infection and 25 patients who had tuberculosis without HTLV-1. All patients with tuberculosis consecutively admitted to Hospital Especializado Octávio Mangabeira (HEOM), Salvador, Brazil, from August 2007 to July 2009 were tested for HTLV-1 by ELISA and those who tested positive underwent confirmation by a Western blot test. The inclusion criteria were age between 18 to 60 years, diagnosis of tuberculosis with documentation of acid-fast bacilli (AFB) by microscopy in the sputum and serologic test for HTLV1. Exclusion criteria included pregnant women, patients with diabetes, kidney failure, HIV infection and use of immunosuppressive drugs. For each patient with tuberculosis and HTLV-1 infection, two controls with only tuberculosis matched by gender and age plus or minus five years of age were included. A case was defined as a patient with two sputum tests positive for AFB by microscopy and a positive ELISA test for HTLV-1 confirmed by Western blot. A standardized questionnaire soliciting demographic and clinical information was completed for each participant at the time of enrolment into the study. A pulmonary specialist (MLB) examined each patient and reviewed laboratory test and the $\mathrm{x}$-ray results. The patients were evaluated at entrance into the study, and at 10, 20 and 30 days after admission. An informed consent was obtained from all participants and the study was approved by the Ethical Committee of the HEOM.

\section{Laboratory tests}

The TST was performed by trained nursing staff at HEOM with $0.1 \mathrm{ml}$ of PPD RT23 (2 tuberculin unit [TU], Statens Serum Institute, Copenhagen, Denmark). The reaction was read $72 \mathrm{~h}$ later. The cut-off point for a positive reaction was $>5 \mathrm{~mm}$ induration.

Serum samples were screened for antibodies to HTLV1 by ELISA (Murex HTLV-1, Abbot, Dartford, UK) and confirmed by a Western blot analysis (HTLV Blot2.4, Genelabs, Singapore) performed in accordance with the manufaturer's instructions. Samples were also screened for antibodies to HIV-1 by ELISA (Ortho-Clinical Diagnostics, Raritan, NJ, USA). Sputum of each patient was examined by the Ziehl-Neelsen staining method and the bacillary load was classified as $1+, 2+, 3+$ or negative. Culture of the sputum was also performed in Lowenstein-Jensen culture media.

\section{Immunological studies}

Peripheral blood mononuclear cells (PBMC) were obtained from heparinized venous blood by density gradient centrifugation using Ficoll-Hypaque (Sigma Chemical Co, St. Louis, MD, USA). After washing with saline, the cells were adjusted to $3 \times 10^{6} \mathrm{ml}$ and cultured in RPMI 1640 (GIBCO Grand Island, NY, USA) plus 5\% heat inactivated human $\mathrm{AB}$ serum supplemented with gentamicin and glutamine. Cells were incubated only with medium or stimulated with PPD at concentration of $1 \mu \mathrm{g} / \mathrm{ml}$ for 72 hours at $37^{\circ} \mathrm{C}$ in $5 \% \mathrm{CO}_{2}$. Determination of TNF- $\alpha$, IFN- $\gamma$ and IL-10 was performed by ELISA with monoclonal anti cytokine antibodies [3]. Data expressed in $\mathrm{pg} / \mathrm{ml}$ represent the amount of protein detected in the supernatants of cultures. The mRNA for IL-12 was performed by real time PCR. HTLV-1 seronegative individuals were used as controls. RNA from cell lysates was isolated in Tri Reagent Solution (Ambion, Applied Biosystems, Foster City, CA, USA). The concentration and purity of RNA as well as DNA synthesis were assessed as previously described [31]. Briefly, for relative quantitative Real Time PCR cDNA specific primers for IL-12 and reference gene HPRT were purchased from RealTimePrimers.com (Real Time primers, LLC, 7304 Mountain Ave, Elkins Park, PA 19027, USA). Relative quantitative PCR reactions were performed on a Real-Time PCR system Step OnePLUS AB Applied Biosystems in a 96-well microtiter plate and a final volume of $10 \mu \mathrm{L}$ using $0-5 \mu \mathrm{L}$ of cDNA, $2-5 \mu \mathrm{L}$ of 2X SYBR Green Master mix (AB Applied Biosystems, Foster City, CA, USA) and $30 \mathrm{pM}$ specific primer mix. The cycling conditions were as follows: 10 min polymerase activation at $95^{\circ} \mathrm{C}$ followed by 50 cycles of $15 \mathrm{~s}$ at $95^{\circ} \mathrm{C}$ and $1 \mathrm{~min}$ at $60^{\circ} \mathrm{C}$. All samples were amplified in duplicate, and two negative controls per primer pair were included in each run. Melting curve analysis was performed immediately after amplifications. HPRT mRNA expression was used for normalization. Relative expression levels were obtained as mean $\triangle \mathrm{CT}$ for each gene using the software Step OnePLUS ${ }^{\mathrm{TM}}$ Software v2.0 (AB Applied Biosystems). Data for stimulated cultures represent the production of cytokine obtained in culture stimulated with PPD. In some experiments IL-12 and anti-IL-10 were added to the cultures and IFN- $\gamma$ was measured in supernatants.

The HTLV-1 proviral load was performed after DNA extraction from mononuclear cells as previously described [9]. 


\section{Statistical analysis}

Hospitalized pulmonary TB patients with HTLV-1 were compared to control patients without HTLV-1 by Student $t$-test for continuous variables and Pearson $x^{2}$ test for categorical variables. Fisher's exact test was used when one the comparison groups had an expected frequency of five or less. Kaplan-Meier survival analysis was used to compare sputum microscopy conversion after 10 and 20 days of tuberculosis treatment. Comparison of TNF- $\alpha$, IL-12 and IFN- $\gamma$ production between the groups was performed by the Mann Whitney U Test. All analysis was performed with statistical software STATA 10.1 (Stata Corp, College Station, TX, USA).

\section{Competing interests}

The authors declare that they have no competing interests.

\section{Authors' contribution}

MLB was responsible for the clinical evaluation of the patients, $X$-ray analysis, data analysis and preparation of the manuscript. $\mathrm{OB}, \mathrm{TB}, \mathrm{IC}, \mathrm{IB}, \mathrm{FB}$ and DP assisted MLB in the clinical evaluation and followed the patients during hospitalization. BF and LR performed the statistical analysis and review of the manuscript. SS, AS and EMC were responsible for immunological studies. MLB, EMC and LR also participated of the study design, data analysis and in the preparation of the manuscript. All authors read and approved the final manuscript.

\section{Acknowledgements}

The authors thank Elbe Silva for secretarial assistance in the preparation of the manuscript and the nurse N. Pimentel who collected the blood of the patients.

This study was supported by NIH grant \# R01 Al079238. EMC is a senior investigator of CNPq.

\section{Author details}

'Serviço de Imunologia do Complexo Hospitalar Universitário Professor Edgard Santos, Universidade Federal da Bahia, Salvador, BA, Brazil. ${ }^{2}$ Escola Bahiana de Medicina e Saúde Pública, Salvador, BA, Brazil. ${ }^{3}$ Hospital Especializado Octávio Mangabeira, Salvador, BA, Brazil. ${ }^{4}$ University of California at Berkeley, Berkeley, USA. Instituto Nacional de Ciência e Tecnologia de Doenças Tropicais (CNPq/MCT), Salvador, BA, Brazil. "'Serviço de Imunologia, 5 andar, Hospital Universitário Professor Edgard Santos, Rua João das Botas s/n, Canela, Salvador, BA 40110-160, Brazil.

Received: 6 January 2012 Accepted: 13 August 2012

Published: 28 August 2012

\section{References}

1. Proietti FA, Carneiro-Proietti AB, Catalan-Soares BC, Murphy EL: Global epidemiology of HTLV-I infection and associated diseases. Oncogene 2005, 24:6058-6068.

2. Jacobson S: Immunopathogenesis of human T cell lymphotropic virus type I-associated neurologic disease. J Infect Dis 2002, 186(Suppl 2):S187-S192.

3. Santos SB, Porto AF, Muniz AL, de Jesus AR, Magalhaes E, Melo A, Dutra WO, Gollob KJ, Carvalho EM: Exacerbated inflammatory cellular immune response characteristics of HAM/TSP is observed in a large proportion of HTLV-I asymptomatic carriers. BMC Infect Dis 2004, 4:7.

4. Brites C, Weyll M, Pedroso C, Badaro R: Severe and Norwegian scabies are strongly associated with retroviral (HIV-1/HTLV-1) infection in Bahia, Brazil. Aids 2002, 16:1292-1293.

5. Gotuzzo E, Terashima A, Alvarez H, Tello R, Infante R, Watts DM, Freedman DO: Strongyloides stercoralis hyperinfection associated with human $T$ cell lymphotropic virus type-1 infection in Peru. Am J Trop Med Hyg 1999, 60:146-149.
6. Marinho J, Galvao-Castro B, Rodrigues LC, Barreto ML: Increased risk of tuberculosis with human T-lymphotropic virus-1 infection: a casecontrol study. J Acquir Immune Defic Syndr 2005, 40:625-628.

7. Neva FA, Murphy EL, Gam A, Hanchard B, Figueroa JP, Blattner WA: Antibodies to Strongyloides stercoralis in healthy Jamaican carriers of HTLV-1. N Engl J Med 1989, 320:252-253.

8. Pedral-Sampaio DB, Martins Netto E, Pedrosa C, Brites C, Duarte M, Harrington W Jr: Co-Infection of Tuberculosis and HIV/HTLV Retroviruses: Frequency and Prognosis Among Patients Admitted in a Brazilian Hospital. Braz J Infect Dis 1997, 1:31-35.

9. Porto AF, Santos SB, Muniz AL, Basilio V, Rodrigues W Jr, Neva FA, Dutra WO, Gollob KJ, Jacobson S, Carvalho EM: Helminthic infection downregulates type 1 immune responses in human T cell lymphotropic virus type 1 (HTLV-1) carriers and is more prevalent in HTLV-1 carriers than in patients with HTLV-1-associated myelopathy/tropical spastic paraparesis. $J$ Infect Dis 2005, 191:612-618.

10. Montes M, Sanchez C, Verdonck K, Lake JE, Gonzalez E, Lopez G, Terashima A, Nolan T, Lewis DE, Gotuzzo E, White AC Jr: Regulatory T cell expansion in HTLV-1 and strongyloidiasis co-infection is associated with reduced IL-5 responses to Strongyloides stercoralis antigen. PLoS Negl Trop Dis 2009, 3:e456.

11. Neva FA, Filho JO, Gam AA, Thompson R, Freitas V, Melo A, Carvalho EM: Interferon-gamma and interleukin-4 responses in relation to serum IgE levels in persons infected with human T lymphotropic virus type I and Strongyloides stercoralis. J Infect Dis 1998, 178:1856-1859.

12. Porto AF, Neva FA, Bittencourt $H$, Lisboa W, Thompson R, Alcantara $L$, Carvalho EM: HTLV-1 decreases Th2 type of immune response in patients with strongyloidiasis. Parasite Immunol 2001, 23:503-507.

13. de Lourdes Bastos M, Osterbauer B, Mesquita DL, Carrera CA, Albuquerque MJ, Silva L, Pereira DN, Riley L, Carvalho EM: Prevalence of human T-cell lymphotropic virus type 1 infection in hospitalized patients with tuberculosis. Int J Tuberc Lung Dis 2009, 13:1519-1523.

14. Verdonck K, Gonzalez E, Henostroza G, Nabeta P, Llanos F, Cornejo H, Vanham G, Seas C, Gotuzzo E: HTLV-1 infection is frequent among outpatients with pulmonary tuberculosis in northern Lima, Peru. Int I Tuberc Lung Dis 2007, 11:1066-1072.

15. Verdonck K, Gonzalez E, Schrooten W, Vanham G, Gotuzzo E: HTLV-1 infection is associated with a history of active tuberculosis among family members of HTLV-1-infected patients in Peru. Epidemiol Infect 2008, 136:1076-1083.

16. Murai K, Tachibana N, Shioiri S, Shishime E, Okayama A, Ishizaki J, Tsuda K, Mueller N: Suppression of delayed-type hypersensitivity to PPD and PHA in elderly HTLV-I carriers. J Acquir Immune Defic Syndr 1990, 3:1006-1009.

17. Tachibana N, Okayama A, Ishizaki J, Yokota T, Shishime E, Murai K, Shioiri S, Tsuda K, Essex M, Mueller N: Suppression of tuberculin skin reaction in healthy HTLV-I carriers from Japan. Int J Cancer 1988, 42:829-831.

18. Welles SL, Tachibana N, Okayama A, Shioiri S, Ishihara S, Murai K, Mueller NE: Decreased reactivity to PPD among HTLV-I carriers in relation to virus and hematologic status. Int I Cancer 1994, 56:337-340.

19. Mascarenhas RE, Brodskyn C, Barbosa G, Clarencio J, Andrade-Filho AS, Figueiroa F, Galvao-Castro B, Grassi F: Peripheral blood mononuclear cells from individuals infected with human T-cell lymphotropic virus type 1 have a reduced capacity to respond to recall antigens. Clin Vaccine Immunol 2006, 13:547-552.

20. Matos ED, Moreira Lemos AC: Association between serum albumin levels and in-hospital deaths due to tuberculosis. Int J Tuberc Lung Dis 2006, 10:1360-1366.

21. Suzuki M, Dezzutti CS, Okayama A, Tachibana N, Tsubouchi H, Mueller N, Lal RB: Modulation of T-cell responses to a recall antigen in human T-cell leukemia virus type 1-infected individuals. Clin Diagn Lab Immunol 1999, 6:713-717.

22. Carvalho EM, Bacellar O, Porto AF, Braga S, Galvao-Castro B, Neva F: Cytokine profile and immunomodulation in asymptomatic human Tlymphotropic virus type 1-infected blood donors. J Acquir Immune Defic Syndr 2001, 27:1-6.

23. Santos SB, Porto AF, Muniz AL, Luna T, Nascimento MC, Guerreiro JB, Oliveira-Filho J, Morgan DJ, Carvalho EM: Modulation of T cell responses in HTLV-1 carriers and in patients with myelopathy associated with HTLV-1. Neuroimmunomodulation 2006, 13:145-151.

24. de Noronha AL, Bafica A, Nogueira L, Barral A, Barral-Netto M: Lung granulomas from Mycobacterium tuberculosis/HIV-1 co-infected patients 
display decreased in situ TNF production. Pathol Res Pract 2008, 204::155-161.

25. Holscher C, Holscher A, Ruckerl D, Yoshimoto T, Yoshida H, Mak T, Saris C, Ehlers S: The IL-27 receptor chain WSX-1 differentially regulates antibacterial immunity and survival during experimental tuberculosis. $J$ Immunol 2005, 174:3534-3544

26. Uchida Y, Casali N, White A, Morici L, Kendall LV, Riley LW: Accelerated immunopathological response of mice infected with Mycobacterium tuberculosis disrupted in the mce1 operon negative transcriptional regulator. Cell Microbiol 2007, 9:1275-1283.

27. Algood HM, Lin PL, Flynn JL: Tumor necrosis factor and chemokine interactions in the formation and maintenance of granulomas in tuberculosis. Clin Infect Dis 2005, 41(Suppl 3):S189-S193.

28. Wallis RS, Broder M, Wong J, Lee A, Hoq L: Reactivation of latent granulomatous infections by infliximab. Clin Infect Dis 2005, 41(Suppl 3):S194-S198.

29. Flynn JL, Chan J: Immune evasion by Mycobacterium tuberculosis: living with the enemy. Curr Opin Immunol 2003, 15:450-455.

30. Jo EK, Yang $\mathrm{CS}$, $\mathrm{Choi} \mathrm{CH}$, Harding $\mathrm{CV}$ : Intracellular signalling cascades regulating innate immune responses to Mycobacteria: branching out from Toll-like receptors. Cell Microbiol 2007, 9:1087-1098.

31. Novoa R, Bacellar O, Nascimento M, Cardoso TM, Ramasawmy R, Oliveira WN, Schriefer A, Carvalho EM: IL-17 and Regulatory Cytokines (IL-10 and IL-27) in L. braziliensis Infection. Parasite Immunol 2011, 33:132-136.

doi:10.1186/1471-2334-12-199

Cite this article as: Bastos et al:: Influence of HTLV-1 on the clinical microbiologic and immunologic presentation of tuberculosis. BMC Infectious Diseases 2012 12:199.

\section{Submit your next manuscript to BioMed Central and take full advantage of:}

- Convenient online submission

- Thorough peer review

- No space constraints or color figure charges

- Immediate publication on acceptance

- Inclusion in PubMed, CAS, Scopus and Google Scholar

- Research which is freely available for redistribution 